\title{
Microscopic examination of bone marrow aspirates in malignant disorders of haematopoiesis-a comparison of two slide preparation techniques
}

\author{
Krzysztof Lewandowski • Agnieszka Complak • \\ Andrzej Hellmann
}

Received: 19 August 2011 / Accepted: 25 September 2011 /Published online: 12 October 2011

(C) The Author(s) 2011. This article is published with open access at Springerlink.com

\begin{abstract}
It is mandatory to perform microscopic examinations of bone marrow aspirates during the diagnosis of many neoplastic haematopoiesis disorders. In 2008, The International Committee for Standardization in Hematology recommended the use of two types of slides for the microscopic evaluation of bone marrow: wedge-spread film and crush film slides. Because these techniques have not yet been compared, we performed such a comparison. Routine bone marrow samples from 250 patients diagnosed due to different neoplastic haematological disorders were evaluated. The major differences between the two compared techniques were identified in 13 patients with non-Hodgkin's lymphoma, seven patients with systemic mastocytosis and 11 patients with acute leukaemias or myelodysplastic syndromes or chronic myelomonocytic leukaemia. Differences were noted also in many patients with multiple myeloma, but the clinical significance of these discrepancies was rather modest. The major causes of the differences observed seemed to be the dilution of marrow with blood cells and the focal growth of many neoplastic cells. We believe that the crush technique is more advantageous compared to the wedge-spread films. Therefore, we recommend the use of crush films as the primary method for establishing a diagnosis or for making therapeutic decisions based on the microscopic examination of bone marrow.
\end{abstract}

K. Lewandowski $(\bowtie) \cdot$ A. Complak

Department of Clinical Chemistry and Biochemistry, Medical University of Gdansk,

Debinki St 7,

80-952 Gdansk, Poland

e-mail: klewa@gd.home.pl

A. Hellmann

Department of Hematology and Transplantology, Medical

University of Gdansk,

Gdansk, Poland
Keywords Bone marrow aspirate examination . Wedge-spread film technique - Crush technique . Malignant disorders of haematopoiesis

\section{Introduction}

The microscopic examination of bone marrow remains one of the key diagnostic procedures in haematology. According to the newest guidelines related to the diagnosis of bone marrow and lymphatic system malignancies issued by the World Health Organization (WHO), the importance of microscopic examinations of bone marrow has not decreased; rather, more precise morphological criteria were defined, where needed, to avoid ambiguity.

For many diseases, more specific immunological or molecular markers have been discovered, which, when compared to microscopic examination, allow for a significantly more precise assessment of atypical cell counts. Nevertheless, such markers are not available for all diseases, and microscopic examination remains the only, or the main, method for diagnosis and monitoring of the therapy implemented. Also, for diseases where the diagnosis is based on genetic methods or immunophenotyping, periodic microscopic examinations of bone marrow are needed in order to quickly check for various presentations of transformation status or secondary dysplastic changes. The WHO classification sets very high expectations for cytologists, as the final diagnosis is often based on properly assessed cellular composition percentages of the bone marrow. In our clinical practice, assessments of bone marrow aspirates from the same patient performed in different laboratories brought different results, although each of the assessments was performed in the appropriate manner. These differences were mostly caused by the 
existence of two slide preparation techniques. The International Committee for Standardization in Hematology (ICSH) recommends the use of two types of slides for the microscopic evaluation of bone marrow: wedge-spread film (technique 1) and crush film (technique 2) slides [1]. The two techniques mentioned above have not yet been compared in terms of relevance for diagnostic and monitoring use in patients with haematological disorders. The aim of this study was to compare the wedge-spread and crush film techniques and to determine which of them is more appropriate for the diagnosis and/or the monitoring of selected groups of haematological disorders.

\section{Materials and methods}

Bone marrow samples were collected from 250 patients diagnosed and treated in the Department of Hematology and Transplantology, Medical University of Gdansk. Bone marrow aspirates were taken from posterior superior iliac spine in accordance with ICSH guidelines [1]. Only bone marrow aspirates containing particles were analysed. Smears from each bone marrow sample were prepared using both techniques by the same technician, within maximum of $20 \mathrm{~min}$ after aspiration. In technique 1, a sample was smeared onto the glass slide using the edge of another glass slide, whereas in technique 2 the particles were squashed between two slides. After staining by the May-Grünwald-Giemsa method, the slides were microscopically examined in accordance with the ICSH guidelines [1]. In the slides prepared according to technique 1, a nucleated differential cell count was performed in the areas just before the marrow particles. In the slides prepared according to technique 2, only well-spread marrow cells around the bone marrow particles were analysed. Areas with significant numbers of damaged cells were avoided. The marrow cellularity was assessed under $\times 100$ and $\times 400$ magnifications and described as: aplastic, very low, low, average, high or increased. The same magnifications were used to assess the megakaryocyte number, described as follows: lack of megakaryocytes, very low number of megakaryocytes, low, average, high or very high number of megakaryocytes. A nucleated differential cell count was then performed in selected areas (Fig. 1). At least 1,000 cells were counted. The cells were identified according to generally accepted standards [2-4]. Quantitative assessments of particular cell lineages were performed under $\times 500$ and $\times 1,000$ magnifications. According to the WHO guidelines, dysplastic changes were qualitatively evaluated in 200 erythropoietic and granulopoietic cells and in 30 megakaryocytes (where possible) [5]. For each patient, slides prepared using both techniques were compared and
Fig. 1 Bone marrow smear prepared using technique 1 (a) and technique 2 (b) at $\times 100$ magnification (upper part of each picture) and at $\times 400$ magnification (lower part of each picture)

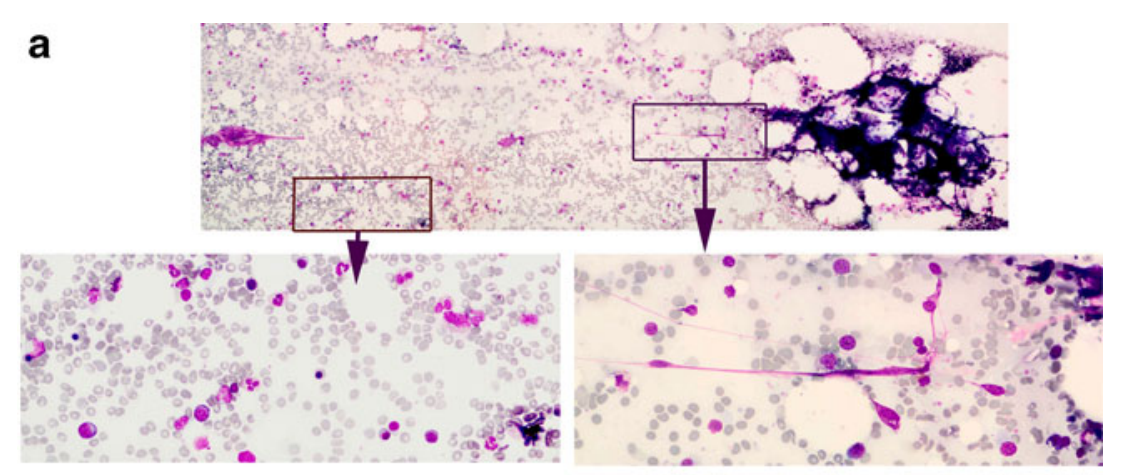

b

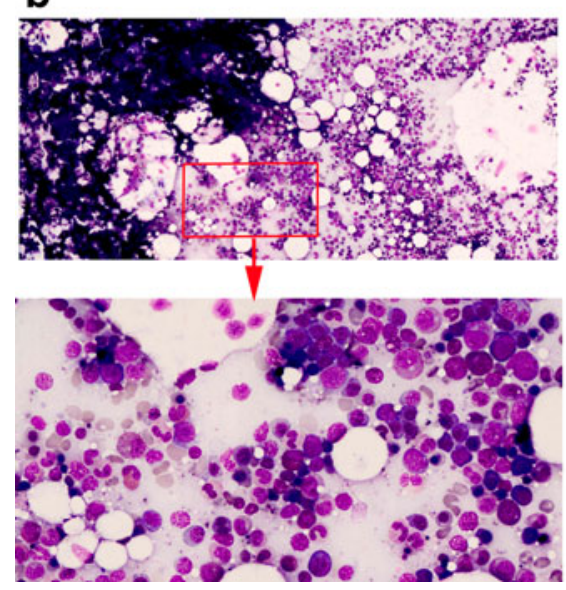


assessed and in each case an attempt was made to analyse the reasons for any potential differences. In order to avoid any bias related to assessments carried out by different operators, all microscopic examinations were performed in a blinded manner by the same person.

\section{Statistical analysis}

The distribution of most variables was not normal (Kolmogorov-Smirnov test, $p<0.1$ ). Therefore, the median (range) was used as a descriptive statistic, and non-parametric tests were applied to verify the hypotheses. The percentages of each bone marrow cell population for each technique were compared using the Wilcoxon test. In the case of categorical variables (cellularity, megakaryocyte count), numbers were assigned to each category and the variables were treated as numerical; $p \leq 0.05$ was considered to be statistically significant.

\section{Results}

Bone marrow aspirates from a group of patients were analysed for the diagnostic procedure, assessment of the stage of the disease and for treatment monitoring of any previously diagnosed diseases. Indications for bone marrow examination are summarized in Table 1.

\section{Non-Hodgkin's lymphoma}

The overall cellularity of the bone marrow was similar regardless of the smear preparation technique used. The total percentage of lymphoid lineage cells (excluding plasma cells) is given in Fig. 2.

Diagnostic value of 12 out of 60 (20\%) smears prepared using technique 1 had a limited adequacy due to significant dilution by peripheral blood; 1 out of 60 smears (2\%) was considered inadequate for diagnostic purposes. The final conclusions drawn from the microscopic examinations of slides from both techniques were in full agreement for 34
(57\%) patients. The conclusions for $13(22 \%)$ patients were slightly different: in seven cases, the smears prepared according to technique 1 contained peripheral blood, which made it difficult to conclude whether infiltration was present or not; in two cases, the smears prepared according to technique 1 included polymorphic lymphatic cells of atypical characteristics, which were not confirmed by technique 2; in three cases for technique 2 , a few clusters of lymphatic cells were observed, which might have been inflammatory lymphatic aggregates, whereas for technique 1 an increased number of lymphatic cells was not seen; in the two last cases, they differ in terms of numbers of eosinophils $(1.0 \%$ for technique 1 and $5.2 \%$ for technique 2 ) and cellularity (average for technique 1 and hypoplastic particles with the visible suppression of granulopoiesis for technique 2), respectively. The details are provided in Table 2.

Plasma cell (multiple) myeloma

Microscopic examinations of bone marrow samples from 14 patients were performed in order to confirm the first diagnosis, and from 10 patients to confirm disease remission. The plasma cell percentages depending on the technique used are presented for both groups in Fig. 3.

All bone marrow slides prepared according to technique 2 were considered adequate. In 8 out of 24 (33\%) slides prepared according to technique 1, marked dilution by peripheral blood was noted. In 1 out of $24(4 \%)$ bone marrow slides prepared according to technique 1, the slide was considered inadequate (almost a complete lack of nucleated cells). An increased number of bone marrow plasma cells were observed in 15 patients. The number of plasma cells was almost always higher in the slides prepared by technique 2 compared to technique 1, with the maximum value being fourfold higher.

Despite differences in the plasma cell counts, the final conclusions were consistent for both techniques in $21(88 \%)$ patients. In the remaining three (12\%) patients, the plasma cell counts in slides prepared according to technique 1 did not
Table 1 Indications for bone marrow examination in the patient study group

\begin{tabular}{|c|c|c|c|}
\hline Diagnosis/suspicion & Diagnostic procedure/staging & Treatment monitoring & Total \\
\hline Non-Hodgkin's lymphoma & 60 & - & 60 \\
\hline Plasma cell myeloma & 14 & 10 & 24 \\
\hline Chronic lymphocytic leukaemia & 21 & - & 21 \\
\hline Acute leukaemias & 18 & 54 & 72 \\
\hline Myelodysplastic syndromes & 38 & - & 38 \\
\hline Chronic myelomonocytic leukaemia & 5 & - & 5 \\
\hline Mastocytosis & 30 & - & 30 \\
\hline Total & & & 250 \\
\hline
\end{tabular}




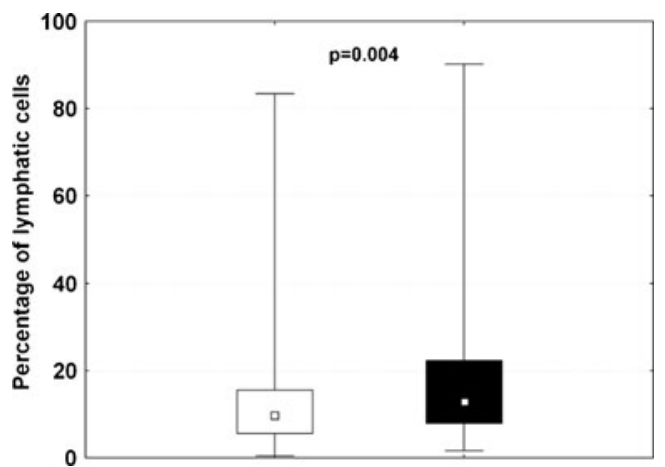

Fig. 2 Comparison of lymphatic cell percentages (excluding plasma cells) in the bone marrow smears prepared using technique 1 (white rectangles) and technique 2 (black rectangles) (open squares median; white bars/black bars range 25-75\%; scale bars min-max)

exceed $10 \%: 8.2 \%, 3.0 \%$ and $3.4 \%$, respectively, whereas in slides prepared according to technique 2 the following values were recorded: $22.3 \%, 10.2 \%$ and $10.2 \%$, respectively.

\section{Systemic mastocytosis}

Microscopic examinations of bone marrow samples were performed in 30 patients to confirm the diagnosis of systemic mastocytosis (SM). Both techniques differ in terms of mast cell count $(p=0.0007)$. In 14 out of 30 patients, the mast cell counts were not increased regardless of the technique used, and there were no atypical mast cell forms. In this group, SM was finally diagnosed in two patients by the use of other examinations (i.e. trephine biopsy, KIT mutation and serum tryptase). In the next 7 out of 30 patients, the mast cell counts were slightly higher (range $0.3-0.8 \%$ ) in slides prepared according to technique 2 , which could suggest SM, whereas in slides from 5 patients prepared using technique 1 there were no mast cells or only a few mast cells were present $(\leq 0.2 \%)$, which did not suggest SM. Slightly increased number of mast cells in slides prepared according to technique 1 were only more frequent for two patients $(0.4 \%$ and $0.7 \%$, respectively), which could suggest SM. Diagnosis of SM was finally confirmed in five patients from this group. In the remaining 9 out of 30 patients, who had a later confirmation of an SM diagnosis, the mast cell counts in slides prepared using technique 2 were significantly higher, which suggested an SM diagnosis. A comparison of conclusions from bone marrow examination using both techniques in the last group of patients is presented in Table 3 .

\section{B-cell chronic lymphocytic leukaemia}

Bone marrow slides were obtained from 21 patients diagnosed with B-cell chronic lymphocytic leukaemia (B-CLL). The percentage of lymphocytic cells did not differ between the slides prepared using both techniques (Fig. 4).

Lymphocytic infiltration in slides prepared using technique 2 was often irregular, causing some difficulties in assessing the percentages of this cell lineage. This observation, however, had no influence on the final conclusions, which were either similar or identical in certain patients.

Table 2 Differences in the conclusions drawn from the microscopic examination of slides prepared according to techniques 1 and 2 in patients with NHL

\begin{tabular}{|c|c|c|c|c|c|}
\hline \multirow[t]{2}{*}{ No. } & \multicolumn{2}{|l|}{ Technique 1} & \multicolumn{2}{|l|}{ Technique 2} & \multirow{2}{*}{$\begin{array}{l}\text { Infiltration confirmed in } \\
\text { pathological examination }\end{array}$} \\
\hline & $\begin{array}{l}\text { Percentage } \\
\text { lymphocytic cells }\end{array}$ & Conclusion & $\begin{array}{l}\text { Percentage } \\
\text { lymphocytic cells }\end{array}$ & Conclusion & \\
\hline 1 & 8.0 & No infiltration & 7.8 & Focal infiltration & Yes \\
\hline 2 & 5.8 & No infiltration & 35.5 & Focal infiltration & Yes \\
\hline 3 & 11.6 & No infiltration & 12.2 & $\begin{array}{l}\text { Focal infiltration, low marrow } \\
\text { cellularity }\end{array}$ & Not performed \\
\hline 4 & 9.0 & No infiltration & 30.8 & Wide-spread infiltration & Yes \\
\hline 5 & 16.2 & No infiltration & 27.9 & Focal infiltration & Not performed \\
\hline 6 & 3.6 & No infiltration & 13.5 & Focal infiltration & Yes \\
\hline 7 & 9.4 & No infiltration & 26.3 & Focal infiltration & Not performed \\
\hline 8 & 6.6 & $\begin{array}{l}\text { No infiltration, } \\
\text { eosinophils }-7.8 \%\end{array}$ & 29.7 & $\begin{array}{l}\text { Wide-spread infiltration, } \\
\text { eosinophils- } 14.8 \%\end{array}$ & Yes \\
\hline 9 & 15.0 & $\begin{array}{l}\text { No infiltration, blood } \\
\text { addition }\end{array}$ & 19.5 & $\begin{array}{l}\text { Focal infiltration, } \\
\text { haemophagocytosis }\end{array}$ & Not performed \\
\hline 10 & 17.8 & No infiltration & 15.3 & Focal infiltration & Yes \\
\hline 11 & 18.0 & No infiltration & 48.3 & Wide-spread infiltration & Not performed \\
\hline 12 & 11.9 & No infiltration & 18.6 & Infiltration in $3 / 5$ & Not performed \\
\hline 13 & 6.8 & No infiltration & 19.5 & Infiltration & Yes \\
\hline
\end{tabular}


Fig. 3 Comparison of plasma cell percentages in bone marrow from patients with plasma cell myeloma (a at the time of diagnosis; b after therapy); smears prepared using technique 1 (white rectangles) and technique 2 (black rectangles) (open squares median; white bars/ black bars range 25-75\%; scale bars min-max)
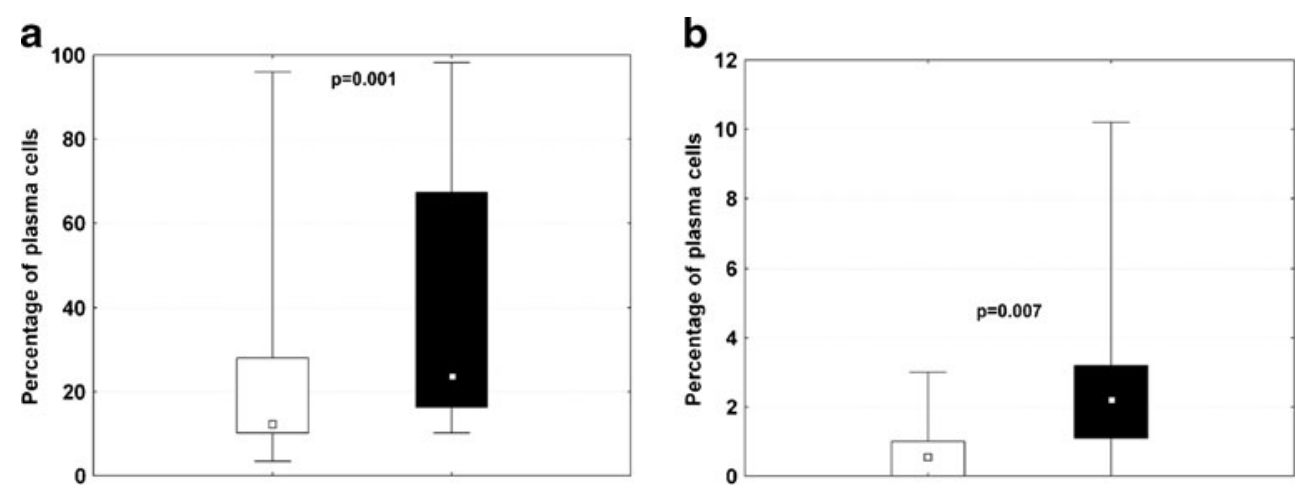

Acute leukaemia, myelodysplastic syndromes and chronic myelomonocytic leukaemia

Bone marrow smears from 61 patients with suspected acute leukaemia, myelodysplastic syndrome or chronic myelomonocytic leukaemia were examined. Taking into account all of the diagnostic procedures, acute leukaemia (AL) was confirmed in 21 patients (microscopic examination of bone marrow aspirates was indicative of AL in 21 slides prepared using technique 2 and 16 slides prepared using technique 1); myelodysplastic syndromes (MDS) was confirmed in 11 patients (microscopic examination of bone marrow aspirates was indicative of MDS in 11 slides prepared using technique 2 and 10 slides prepared using technique 1) and chronic myelomonocytic leukaemia (CMML) was diagnosed in 5 patients (microscopic examination of bone marrow aspirates was indicative of CMML in all slides regardless of the preparation technique). The median percentages of blast cells in the AL and MDS and CMML groups differed between the slides prepared using techniques 1 and 2 (Fig. 5).

In the whole group of patients with a diagnosis of a myeloid neoplasm, major differences depending on the technique used to prepare the slides were found in 11 cases (Table 4).
Bone marrow samples from 54 patients were examined to assess remission status. The aspirates were collected during various moments of the treatment course. Blast counts were similar for both slide preparation techniques in patient groups with acute myeloblastic and lymphoblastic leukaemia. Therefore, both groups were analysed together. The percentage of blast cells in slides prepared using technique 1 were in the range of 0-94.4 (median, 1.1\%), while in slides prepared using technique 2 they were in the range of 0.2-94.1 (median, $1.8 \%$ ). This difference was significant.

A blast cell percentage $>5 \%$, indicating a lack of cytological remission, was diagnosed in 12 patients when slides prepared using technique 2 were assessed, and in only seven patients for the slides prepared using technique 1. Despite the lack of a clear increase in blast cells in slides prepared using technique 1 , a significant increase was indicated for technique 2 in the slides of five patients. The numerical values are presented in Table 5 .

\section{Discussion}

The microscopic examination of bone marrow will long remain one of the most important diagnostic procedures in haematology. Therefore, it is very important to be aware
Table 3 Mast cell percentages in bone marrow samples from nine patients
The microscopic examination of slides prepared according to technique 2 was indicative of $\mathrm{SM} /$ mast cell leukaemia (MCL) in this group

\begin{tabular}{|c|c|c|c|c|}
\hline \multirow[t]{2}{*}{ No. } & \multicolumn{2}{|l|}{ Technique 1} & \multicolumn{2}{|l|}{ Technique 2} \\
\hline & $\%$ Mast cells & Comments & $\%$ Mast cells & Comments \\
\hline 1 & 0.4 & Few mast cells & 4.6 & Wide-spread focal infiltrations \\
\hline 2 & 0.2 & Very few mast cells & 2.2 & Numerous mast cells in focal aggregates \\
\hline 3 & 10.4 & Picture typical of SM & 55.7 & Mast cell leukaemia \\
\hline 4 & 0 & No mast cells & 0.7 & Few aggregates of atypical mast cells \\
\hline 5 & 0 & No mast cells & 0.9 & Aggregates of atypical mast cells \\
\hline 6 & 8.6 & Picture typical of SM & 12.1 & Picture typical of SM \\
\hline 7 & 0.4 & Few mast cells & 4.4 & Picture typical of SM \\
\hline 8 & 0.2 & Very few mast cells & 5.5 & Wide-spread focal infiltrations \\
\hline 9 & 0.6 & Few mast cells & 3.6 & Numerous mast cells in focal aggregates \\
\hline
\end{tabular}




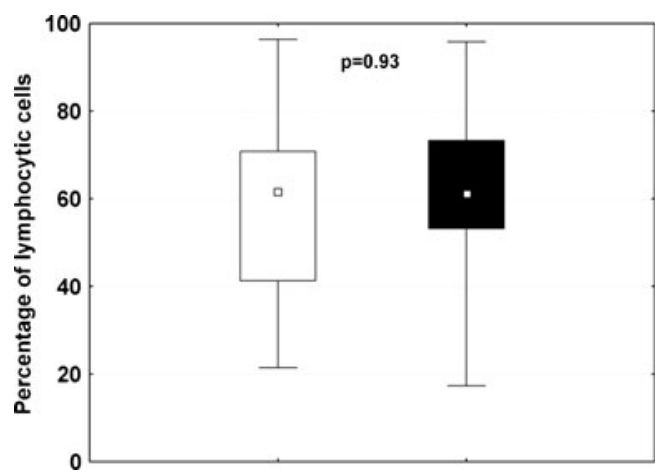

Fig. 4 Comparison of lymphocytic cells in bone marrow smears prepared using technique 1 (white rectangles) and technique 2 (black rectangles) in patients with diagnosed B-CLL. (open squares median; white bars/black bars range 25-75\%; scale bars min-max)

that the examination may reveal diagnostic results characteristic for different diseases depending on the technique of slide preparation used. Although we indicated some differences that seemed to depend on the slide preparation technique used in all groups of neoplastic haematopoietic diseases, not all of them were clinically relevant. For example, regardless of the technique used, lymphocytic infiltration was diagnostic for BCLL. However, in most of the remaining groups of disorders, the differences between the results revealed by microscopic examination that depended on the technique used were of critical significance.

\section{Non-Hodgkin's lymphoma}

Assessment of lymphocytic infiltration in non-Hodgkin's lymphoma during the microscopic examination of bone marrow is always difficult due to at least two reasons. Firstly, bone marrow infiltration is often focal; secondly, some lymphoma cells originating from peripheral lymph system may relocate to bone marrow with blood, sometimes suggesting infiltration of a limited degree. The

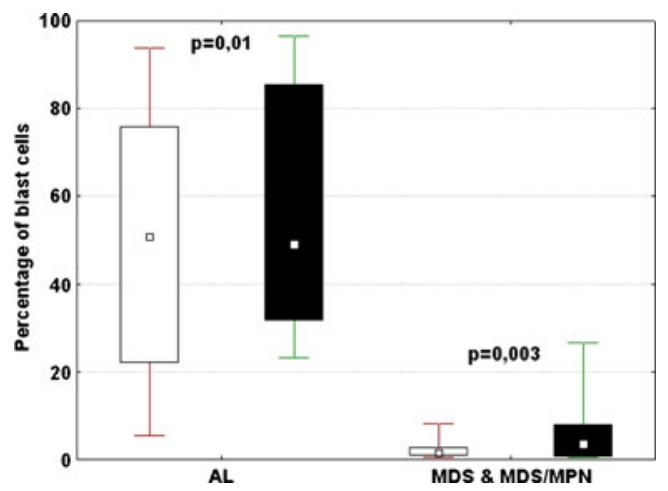

Fig. 5 Comparison of blast cell percentages in bone marrow from patients with AL and MDS and CMML in smears prepared using technique 1 (white rectangles) and technique 2 (black rectangles) (open squares median; white bars/black bars range 25-75\%; scale bars $\min -\max )$ comparison performed indicated that technique 2 was the more useful for assessing bone marrow infiltration by lymphoproliferative processes, mostly of focal characteristic, which is in line with the published guidelines [1]. The conclusion drawn from the slides prepared using this technique correlated better with the trephine biopsy examination results. Technique 2 causes certain interpretation difficulties, particularly when benign lymphocytic aggregates are present in the bone marrow, which may appear in both normal bone marrow and bone marrow affected by inflammatory process. Such aggregates can differ in size, are well delimited from surrounding haematopoietic cells, and mostly consist of numerous mature lymphocytes, with a few lymphoid cells, histiocytes, plasma cells and macrophages located among the lymphocytes. The frequency of lymphoid aggregates present in bone marrow aspirates does not usually exceed $20 \%$; however, in autopsy examinations they were seen in $62 \%$ of biopsies [6,7]. The cell composition of such lymphoid cell aggregate can often suggest their character. A high percentage of more or less polymorphic lymphoid forms, instead of mature lymphocytes, can indicate malignant infiltration. Flow cytometry is often cited as a method that allows verification of the clonal origin of such aggregates [6]. However, a negative result from flow cytometry examination does not exclude the fact that neoplastic lymphoid aggregates might still be present in bone marrow. Due to the above reasons, the most objective examination technique for confirming focal lymphoproliferative infiltration in bone marrow is trephine biopsy [8].

\section{Multiple myeloma}

During the last few years, the diagnostic criteria for multiple myeloma have changed significantly, and currently the plasma cell percentage in bone marrow is not considered crucial for confirming the diagnosis. The plasma cell counts of $\geq 30 \%$ and $10-29 \%$, defined as "major" and "minor" multiple myeloma criteria (according to the previous WHO classification), are not used anymore. It is thought that the plasma cell percentage confirmed during the first diagnosis in the majority of patients is $\geq 10 \%$. This condition is not fulfilled in approximately $10 \%$ of patients with multiple myeloma (MM) [9]. In this study, we showed that differences in plasma cell percentages are particularly high depending on the slide preparation technique used as a consequence of the nature of aggregate growth of plasma cells in bone marrow. Therefore, routine pathology examinations and the use of technique 2 for microscopic examinations are fully justified. Currently, in order to confirm a diagnosis of $\mathrm{MM}$, it is necessary to demonstrate that plasma cell clone is present in the bone marrow, which needs other methods, for instance flow cytometry. Flow 
Table 4 Differences in the microscopic examinations of bone marrow aspirates depending on the preparatory technique used in relation to the type or subtype of AL, MDS or CMML, as observed in 11 patients

\begin{tabular}{|c|c|c|c|c|}
\hline \multirow[t]{2}{*}{ No. } & \multicolumn{2}{|c|}{ Technique 1} & \multicolumn{2}{|c|}{ Technique 2} \\
\hline & $\%$ Blasts & Diagnosis/comments & $\%$ Blasts & Diagnosis/comments \\
\hline 1 & 40.4 & AML with maturation & 58.0 & AML without maturation \\
\hline 2 & 18.6 & MDS-RAEB-2 & 28.4 & AML with multilineage dysplasia \\
\hline 3 & 18.4 & MDS-RAEB-2 & 31.2 & AML with maturation \\
\hline 4 & 17.2 & MDS-RAEB-2 & 25.4 & AML with multilineage dysplasia \\
\hline 5 & 5.4 & MDS-RAEB-1 & 22.8 & AML with multilineage dysplasia \\
\hline 6 & 15.4 & MDS-RAEB-2 & 32.6 & AML with multilineage dysplasia \\
\hline 7 & 4.8 & MDS-RA & 12.8 & MDS-RAEB-2 \\
\hline 8 & 2.0 & Without clear MDS features & 16.1 & MDS-RAEB-2 \\
\hline 9 & 1.4 & Unclear picture & 8.2 & MDS-RAEB-1 \\
\hline 10 & 3.8 & MDS-RCMD & 7.0 & MDS-RAEB-1 \\
\hline 11 & 8.2 & CMML-1 & 14.1 & CMML-2 \\
\hline
\end{tabular}

cytometry, however, should not be considered as a substitute for microscopic examination [10]. The authors demonstrated that although flow cytometric evaluation confirms the presence of plasma cell clones in bone marrow, the percentage of plasma cells is much lower than found in morphological examinations, often not exceeding even $5 \%$. Therefore, it seems justified to not recommend flow cytometry for assessing the scale of plasma cell infiltration, which instead should be assessed using pathological examinations or microscopic evaluations with slides prepared using technique 2 .

Systemic mastocytosis

Mast cells, being part of bone marrow stroma, are mainly localized in bone marrow particles. Thus these cells are rarely seen at a distance from particles, and if a few distant mast cells are present in the slide prepared according to technique 1, it may suggest that the real number of mast cells in the bone marrow is actually much higher. Such an increase, however, does not provide any information about the reason for this increase in mast cell numbers, which might be due to a reactive inflammatory process. Mast cell aggregates localized in bone marrow particles strongly

Table 5 Clinically relevant differences in blast cell percentages in bone marrow aspirates collected from patients with AL who were undergoing therapy

\begin{tabular}{lcc}
\hline No. & \% Blast cells, technique 1 & \% Blast cells, technique 2 \\
\hline 1 & 2.2 & 16.9 \\
2 & 4.6 & 61.5 \\
3 & 3.2 & 9.6 \\
4 & 2.2 & 9.1 \\
5 & 1.3 & 12.7 \\
\hline
\end{tabular}

suggest a proliferative process [11]. Such aggregates were observed in most of the slides prepared using technique 2 that were obtained from patients with a finally confirmed SM diagnosis. In the slides prepared using technique 1 , it was impossible to recognize such aggregates in nonsquashed bone marrow particles. With only a few available mast cells, it appears to be impossible to precisely determine the percentage of atypical forms, which constitutes one of the criteria for an SM diagnosis [12]. This is why the microscopic examinations for SM should be performed using slides prepared according to technique 2 . In the slides prepared using technique 1 , the bone marrow picture was generally unclear and ambiguous, with the changes typical of SM only being seen when significant infiltration was present. However, it should be stressed that trephine biopsy remains necessary in every patient suspected of systemic mastocytosis.

Acute leukaemias, myelodysplastic syndromes and chronic myelomonocytic leukaemia

Microscopic bone marrow examination is absolutely critical for the diagnosis of AL, MDS and CMML. The previously used French-American-British classification qualified these neoplasms based only on cytological and cytochemical characteristics [13, 14]. The diagnostic criteria have been significantly improved by adding immunophenotyping, cytogenetic and molecular testing. Many valuable information gives trephine biopsy examination which should always be performed when myelodysplastic syndrome is suspected. Despite of that, microscopic evaluation remains crucial for blast cell percentage discrimination. Additionally, there is no better method for assessing blast counts in bone marrow. Flow cytometry analysis based on CD34+ cell counts cannot replace microscopic examination because not every blast cell expresses the CD34 antigen. 
Moreover, flow cytometry analysis is highly influenced by bone marrow dilution by blood, as well as by bone marrow fibrosis [15]. The aforementioned limitations may lead to falsely low percentages of blast cells. The currently used MDS classification is based not only on confirmation of the presence of enhanced dysplasia, but also on the number of blast cells in blood and bone marrow. This latter parameter is of significant prognostic value, and is included in the three parameters required for establishment of the International Prognostic Scoring System, which in turn is used to make therapeutic decisions [16]. Both techniques of slide preparation were found to be equally sensitive for detecting dysplastic abnormalities. Technique 2 is advantageous with respect to platelet lineage assessment: megakaryocyte counts were generally significantly higher, and details in the shape of nuclei were easier to see. However, if the qualitative characteristics of dysplasia are weak, and the blast count is the dominant abnormality, the use of technique 1 may lead to false negative results, and will not enable a diagnosis of MDS to be confirmed. The differences in blast cell counts in MDS seemed to be related not only to bone marrow dilution with peripheral blood, but also to the tendency of blast cells to aggregate into clusters in bone marrow particles. These particles are clearly visible in trephine biopsy examinations, usually in more advanced forms of MDS [15]. Therefore, we believe that technique 2 is more reliable for MDS diagnosis and better correlated to the clinical picture of patients.

Clinically relevant differences in both techniques of bone marrow preparation are often related to acute leukaemias associated with multilineage myelodysplasia, or to secondary leukaemias. Quite frequently, myelodysplastic syndrome, as indicated in slides prepared using technique 1 , is recognized as acute leukaemia in slides prepared according to technique 2 . Taking into account the possibility of the focal growth of blast cells, for establishing the subtype of bone marrow hyperplasia (MDS or AML), it seems appropriate to use the highest percentage of blast cells from slides prepared using either technique 1 or technique 2. Such an approach would be consistent with the recognition criteria of blast cell crises in chronic myeloid leukaemia [17].

Monitoring the effects of chemotherapy on acute leukaemia possibly requires the most precise diagnostic methods, which are mostly based on immunology and/or molecular techniques. Microscopic examination lost its significance because it does not usually offer the precision required by many current therapeutic schemes. In our study, we showed that it is possible that the assessment of bone marrow using technique 1 was indicative of remission, whereas the examination performed in slides prepared using technique 2 excluded remissions. Flow cytometry examinations should indicate blast counts similar to those found using technique 1 . It should be remembered when making therapeutic decisions that flow cytometry usually has a tendency to reveal a lower blast cell count than there might be in reality.

The results presented confirm that microscopic examinations of bone marrow in patients with one of several neoplastic haematopoietic disorders may provide different results depending on the technique used to prepare the slides. Many of the significant symptoms, easily seen in slides prepared using technique 2 (i.e. focal lymphocytic or mast cell infiltrations) might not be observed in slides prepared using technique 1 . On the other hand, in some specific situations (i.e. presence of villous lymphatic cells), technique 1 could better preserve single cell morphology. Therefore we support in full of the ICSH guidelines which state that microscopic examinations should be performed using slides prepared according to either technique. We believe that technique 2 is more advantageous compared to technique 1. Furthermore, the results obtained using the slides prepared by technique 2 correlated better with the clinical picture and trephine biopsy examination results. Therefore, we recommend the use of technique 2 as the primary method for establishing a diagnosis or for making therapeutic decisions based on microscopic examinations of bone marrow.

Conflict of interests The authors declare no conflict of interest.

Open Access This article is distributed under the terms of the Creative Commons Attribution Noncommercial License which permits any noncommercial use, distribution, and reproduction in any medium, provided the original author(s) and source are credited.

\section{References}

1. Lee SH, Erber WN, Porwit A, Tomonaga M, Peterson LC (2008) ICSH guidelines for the standardization of bone marrow specimens and reports. Int J Lab Haem 30:349-364

2. Theml H, Diem H, Haferlach T (2004) Color atlas of hematology. Thieme, Stuttgart

3. Bain BJ, Clark DM, Wilkins B (2010) Bone marrow pathology. Blackwell Science, Oxford

4. Zini G, Bain B, Bettelheim P, Cortez J, D’Onofrio G, Faber E, Haferlach T, Kacirkova P, Lewandowski K, Matutes E, Maynadié M, Meletis J, Petersen BL, Porwit A, Terpos E, Tichelli A, Vallespí T, Woessner S, Bennett J, Bene MC (2010) A European consensus report on blood cell identification: terminology utilized and morphological diagnosis concordance among 28 experts from 17 countries within the European LeukemiaNet network WP10, on behalf of the ELN Morphology Faculty. Br J Haematol 151:359-364

5. Brunning RD, Bennett JM, Matutes E, Orazi A, Vardiman JW, Thiele J (2008) Refractory cytopenia with multilineage dysplasia. In: Swerdlow SH, Campo E, Harris NL, Jaffe ES, Pileri SA, Stein H, Thiele J, Vardiman JW (eds) WHO Classification of Tumours of Haematopoietic and Lymphoid Tissues. IARC, Lyon, pp 98-99 
6. Girodon F, Favre B, Carli PM, Nash N, Desbiolles N, Tatou E, Maynadié M (2001) Minor dysplastic changes are frequently observed in the bone marrow aspirate in elderly patients without haematological disease. Clin Lab Haematol 23:297-300

7. Maeda K, Hyun BH, Rebuck JW (1977) Lymphoid follicles in bone marrow aspirates. Am J Clin Pathol 67:41-48

8. Thiele J, Zirbes TK, Kvasnicka HM, Fischer R (1999) Focal lymphoid aggregates (nodules) in bone marrow biopsies: differentiation between hyperplasia and malignant lymphoma-a practical guideline. J Clin Pathol 52:294-300

9. International Myeloma Working Group (IMWG) (2003) Criteria for the classification of monoclonal gammopathies, multiple myeloma and related disorders: a report of the International Myeloma Working Group. Br J Haematol 121:749-757

10. Smock KJ, Perkins SL, Bahler DW (2007) Quantitation of plasma cells in bone marrow aspirates by flow cytometric analysis compared with morphologic assessment. Arch Pathol Lab Med 131:951-955

11. Valent P, Horny HP, Escribano L, Longley BJ, Li CY, Schwartz LB, Marone G, Nunez R, Akin C, Sotlar K, Sperr WR, Wolff K, Brunning RD, Parwaresch MR, Austen KF, Lennert K, Metcalfe DD, Vardiman JW, Bennett JM (2001) Diagnostic criteria and classification of mastocytosis: a consensus proposal. Leuk Res 25:603-625

12. Horny HP, Metcalfe DD, Bennett JM, Bain BJ, Akin C, Escribano L, Valent P (2008) Mastocytosis. In: Swerdlow SH, Campo E,
Harris NL, Jaffe ES, Pileri SA, Stein H, Thiele J, Vardiman JW (eds) WHO Classification of Tumours of Haematopoietic and Lymphoid Tissues. IARC, Lyon, pp 54-63

13. Bennett JM, Catovsky D, Daniel MT, Flandrin G, Galton DAG, Gralnick HR, Sultan C (1976) Proposals for the classification of the acute leukaemias (FAB cooperative group). Br J Haematol 33:451-458

14. Bennett JM, Catovsky D, Daniel MT, Flandrin G, Galton DAG, Gralnick HR, Sultan C (1982) Proposals for the classification of the myelodysplastic syndromes. Br J Haematol 51:189-199

15. Brunning RD, Porwit A, Orazi A, Baumann I, Germing U, Vardiman JW, LeBeau MM, Hellstrom-Lindberg E (2008) Myelodysplastic syndromes/neoplasms, overview. In: Swerdlow SH, Campo E, Harris NL, Jaffe ES, Pileri SA, Stein H, Thiele J, Vardiman JW (eds) WHO Classification of Tumours of Haematopoietic and Lymphoid Tissues. IARC, Lyon, pp 88-93

16. Greenberg P, Cox C, LeBeau MM, Fenaux P, Morel P, Sanz G, Sanz M, Valespi T, Hamblin T, Oscier D, Ohyashiki K, Toyama K, Aul C, Mufti G, Bennett JM (1997) International scoring system for evaluating prognosis in myelodysplastic syndromes. Blood 89:2079-2088

17. Vardiman JW, Melo JV, Baccarani M, Thiele J (2008) Chronic myelogenous leukaemia, BCR-ABL1 positive. In: Swerdlow SH, Campo E, Harris NL, Jaffe ES, Pileri SA, Stein H, Thiele J, Vardiman JW (eds) WHO Classification of Tumours of Haematopoietic and Lymphoid Tissues. IARC, Lyon, pp 32-37 